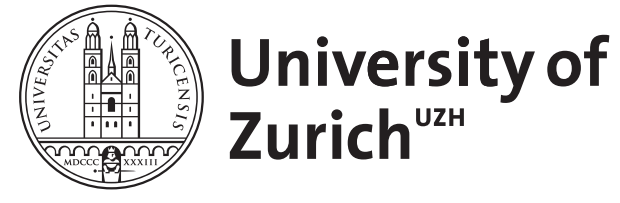

Ein und ist ein oder, und was heißt eigentlich Ehre und Würde? Ambige Syntax und vage Lexik als Probleme der Rechtssprache

\author{
Weiss, Daniel
}

Posted at the Zurich Open Repository and Archive, University of Zurich

ZORA URL: https://doi.org/10.5167/uzh-183324

Book Section

Published Version

Originally published at:

Weiss, Daniel (2019). Ein und ist ein oder, und was heißt eigentlich Ehre und Würde? Ambige Syntax und vage Lexik als Probleme der Rechtssprache. In: Plotnikov, Nikolaj. Gerechtigkeit in Russland : Sprachen, Konzepte, Praktiken. Paderborn: Wilhelm Fink, 107-136. 
Daniel Weiss

\section{Ein und ist ein oder, und was heißt eigentlich Ehre und Würde? Ambige Syntax und vage Lexik als Probleme der Rechtssprache}

Der thematische Komplex ,Sprache und Recht' hat in den letzten Jahren eine beachtliche Ausweitung erfahren; davon zeugen neben eigenen Fachzeitschriften wie dem „International Journal of Speech Language and the Law“ (s.u.), Auswahlbibliographien wie jene zu Recht und Kommunikation (home. edo.uni-dortmund.de/ hoffmann/Biblios/Recht.html) sowie der umfangreichen deutschsprachigen Fachliteratur, die von frühen, noch sehr knapp bemessenen Einführungen ${ }^{1}$ bis zum dreibändigen Kompendium reicht, ${ }^{2}$ nicht zuletzt zahlreiche diesem Gegenstand gewidmete Konferenzen. Deren thematische Spannweite verdeutlichen zwei im Frühjahr 2012 in China veranstaltete Tagungen, darunter die als Fortsetzung der gleichnamigen ersten Konferenz in Hongkong 2010 durchgeführte „2nd International Conference on Law, Language and Discourse. Multiculturalism, Multimodality and Multidimensionality, Zhejiang Police College Hangzhou“, zu deren Objektbereich v.a. gehörten: „Legislative language and discourse, Courtroom language and discourse, Corpus Linguistics and legal discourse, Investigation and Interrogation discourse, Intelligence analysis and legal discourse, Legal lexicography, Law and semiotics" (http://www.zjjcxy.cn/ meeting). Enger fokussiert war die „2nd International Conference on Law, Translation and Culture“, die folgende Themenbereiche abdeckte:

Court interpreting and multimodality. Cultural approach to legal translation/court interpreting, Ethics of legal translators and court interpreters, Fundamentals in legal translation/court interpreting, Language rights and legal translation/court interpreting, Legal bilingualisation/multilingualisation, Legal cultures, Legal discourse and legal translation/court interpreting, Legal translation and semiotics, Training and testing of translators and interpreters in legal settings.

1 M. Nussbaumer: Sprache und Recht; M. Rathert: Sprache und Recht.

2 K. Lerch (Hrsg.): Sprache des Rechts.

(C) WILHELM FINK VERLAG, 2019 | DOI:10.30965/9783846754788_008 
Einem bisher noch nicht erwähnten Aspekt galt eine Tagung in Barcelona im November 2011 zum Thema "Jornadas sobre la Modernización del Lenguaje Jurídico“.

Die forensische Linguistik gehört insbesondere in der angelsächsischen Welt zu den fest etablierten ,hyphen-linguistics' und verfügt über eine eigene Fachvereinigung, eine eigene Homepage und Bibliographie sowie eine jährlich stattfindende Sommerschule. ${ }^{3}$ Eine eigene Subdisziplin stellt die forensische Akustik dar, die der Täteridentifikation dient. Letztere wird öfter als alleiniges Objekt der forensischen Linguistik herausgestellt; ihre gewichtige Stellung verdeutlicht etwa die Fachzeitschrift „The International Journal of Speech Language and the Law“, die sich im Untertitel als „The official journal of the Association of Forensic Linguistics and the International Association for Forensic Phonetics and Acoustics“ zu erkennen gibt (www.equinoxpub.com/ IJSLL). Natürlich erscheinen auch in nichtspezialisierten Zeitschriften einschlägige Beiträge, so etwa in „Pragmatics and Society“ 2/2 (2011) zum Thema „Pragmatics in the courtroom: Violent speech acts, law, and the linguist in France", etc.

Im postsowjetischen Russland hat die forensische Linguistik (Sudebnaja lingvistika) einen wahren Boom erlebt, dem viele Fachkolleginnen und -kollegen eine willkommene Nebenverdienstmöglichkeit als Gerichtsgutachter(innen) verdanken. Der Fokus gilt hier allerdings weniger der Tätererkennung als Straf- und Zivilverfahren zu Ehrverletzungsdelikten; daneben geht es um Tatbestände wie Drohung, (rassistische) Volksverhetzung, aber auch um Werberecht (Markenschutz). Zum Einsatz gelangen in solchen Gutachten v.a. semantische und pragmatische Analysen. ${ }^{4}$

Damit erweist sich die Rechtslinguistik als sehr vielfältige Disziplin, die sowohl Gesetzgebung als auch Rechtsprechung im Visier hat und neben theoretischen auch eminent praktische Zielsetzungen wie die Ausbildung von Gerichtsdolmetschern, die Ausarbeitung bürgernaher Formulierungen von

3 Vgl. International Association of Forensic Linguistics, http://www.iafl.org/; Websters Forensic Linguistics Homepage, http://web.bham.ac.uk/forensic/; Bibliographie zur forensischen Linguistik (englisch), http://www.bham.ac.uk/IAFL/bib/biblio.html.

4 Eine sehr illustrative Einführung in diesen Themenbereich, die im Übrigen in 1000 Exemplaren an Gerichte in der ganzen Russländischen Föderation verteilt wurde, liefert A. Baranov: Lingvističeskaja èkspertiza; der Autor blickt selbst auf 20 Jahre Praxis als Experte vor Gericht zurück und hat dabei ca. 200 Gutachten verfasst. Auch die Monographie von M. Osadčij: Pravovoj samokontrol' beruht auf langjähriger eigener Expertise. K. Brinev: Teoretičeskaja lingvistika stellt die wohl neueste Dissertation zu diesem Bereich dar. Einen Querschnitt durch die ganze Bandbreite der Rechtslinguistik (ebenfalls unter besonderer Berücksichtigung der forensischen Linguistik) vermittelt die in Barnaul erscheinende, auch online verfügbare Zeitschrift Jurislingvistika. 
Gesetzestexten etc. oder der Täteridentifikation in Strafverfahren verfolgt. Im Folgenden soll, wie schon der Titel ankündigt, nur ein schmaler Ausschnitt aus diesem breiten Spektrum behandelt werden: Es geht um Doppeldeutigkeiten und Vagheiten in Syntax und Lexik von Gesetzestexten und ihrer Auslegung vor Gericht. Als Objektsprachen werden neben Russisch im ersten Kapitel auch Englisch und Polnisch beigezogen. Nachdem die Probleme des rechtssprachlichen Vokabulars im öffentlichen Bewusstsein weit besser verankert sind als die Unschärfe der Syntax, soll zunächst letztere behandelt werden.

\section{Die Syntax von Gesetzestexten als Stein des Anstoßes}

Wie der polnischen Tagespresse ${ }^{5}$ zu entnehmen war, wurde am 07.07.2003 eine Verfassungsklage eines Mirosław P. vom polnischen Verfassungsgericht positiv beschieden, die nur die Lokalisierung eines Kommas im Gesetzestext zum Gegenstand hatte. Art. $156 \S 1$ des am 06.06.1997 verabschiedeten polnischen Strafgesetzbuchs statuierte Folgendes:

(1) Kto [....] powoduje inne ciężkie kalectwo, ciężką chorobę nieuleczalną lub długotrwałą chorobę zazwyczaj zagrażającą życiu [...], podlega karze pozbawienia wolności od roku do lat 10.

(Wer [...] eine andere schwere Behinderung, eine schwere unheilbare Krankheit oder eine langwierige gewöhnlich lebensbedrohende Krankheit verursacht $[\ldots]$, unterliegt der Strafe der Freiheitsberaubung von einem bis zu 1o Jahren.)

Dieser Wortlaut war aus der Vorgängerversion von 1969 unverändert übernommen worden mit Ausnahme eines Lapsus: Während der ursprüngliche Text nach dtugotrwata noch ein Komma enthielt, also „[...] ciężką chorobę nieuleczalną lub długotrwałą, chorobę zazwyczaj zagrażającą życiu“ („[...] eine schwere unheilbare oder langwierige Krankheit, eine gewöhnlich lebensbedrohende Krankheit“) lautete, ging das Komma bei der Neuauflage verloren. Nachdem dieser Lapsus bemerkt worden war, wurde es per Verlautbarung der Regierung restituiert. Aufgrund dieses abgeänderten Wortlauts wurde der Angeklagte dann verurteilt und erhob dagegen Verfassungsklage. Diese wurde gutgeheißen, weil das Gericht die Verlautbarung für verfassungswidrig erklärte, und der Täter erhielt das der kommafreien Variante entsprechende

5 Gazeta Wyborcza, 26.02.2007. 
mildere Strafmaß. Noch im selben Jahr beschloss dann der Sejm ordnungsgemäß die Wiedereinführung des Kommas.

Hinter dieser ganzen Schlacht um ein Komma verbirgt sich keineswegs juristische Haarspalterei, sondern ein handfestes syntaktisches Problem, das im Übrigen schon aus den unterschiedlich gegliederten polnischen und deutschen Versionen erhellt: Weil im Deutschen die Stellung adjektivischer Attribute pränominal ist, während im polnischen Original zweimal sowohl präals auch postnominale Position belegt ist (vgl. "ciężkq chorobę nieuleczalna" und „dtugotrwata chorobę [...] zagrażająca [...]"), ließ sich nicht nur keine deutsche Interlinearversion herstellen, sondern auch die alleinig distinktive Rolle des Kommas konnte in der Übersetzung nicht mehr illustriert werden (vgl. die unmögliche Variante ${ }^{*}$,schwere Krankheit unheilbare oder langwierige“).

Versuchen wir nun, die Reichweite der einzelnen durch die Konnektoren i/und bzw. lub/oder verbundenen Konjunkte prädikatenlogisch darzustellen, indem wir die Attribute in Einzelprädikationen verwandeln, so ergeben sich folgende Klammerungen (auf die einbettende wenn-dann-Konstruktion wird der Einfachheit halber verzichtet). Der ursprünglichen Version mit Komma entspricht:

(i) (Krankheit $\mathrm{x}$ ist unheilbar ODE R langwierig) oder (Krankheit $\mathrm{x}$ ist gewöhnlich lebensbedrohend) bzw. mit Aussagenvariablen: $((P \vee Q) x) \vee$ $(\mathrm{Rx})$

Die abgeänderte kommafreie Variante ergibt hingegen

(ii) (Krankheit $\mathrm{x}$ ist unheilbar) ODER (Krankheit $\mathrm{x}$ ist langwierig und gewöhnlich lebensbedrohend) bzw. $(\mathrm{Px}) \vee((\mathrm{Q} \wedge \mathrm{R}) \mathrm{x})$

Dabei markiert Hervorhebung in Kapitälchen einen expliziten, kursive Setzung einen impliziten, d.h. an der Oberfläche verborgenen Konnektor, der der syntaktischen Reihung der Attribute zugrunde liegt. Die juristische Tragweite solch einschneidender Unterschiede bedarf wohl keiner Begründung. Ebenso gilt dies für die Ursache des Übels, nämlich die Unterbestimmtheit bzw. mangelnde Transparenz unserer alltagssprachlichen Syntax: Wir sprechen und schreiben nun einmal nicht in Klammern, damit bleibt die Reichweite der Vorder- und Hinterkonjunkte sowie die Hierarchie der beteiligten Konnektoren (welche Operation soll zuerst ausgeführt werden: die ,und'- oder die ,oder'-Verknüpfung?) häufig im Dunkeln.

Hier zeichnet sich noch ein weiteres aus der Alltagssprache ererbtes Problem ab: Nicht jede Aussagenverknüpfung wird sprachlich explizit markiert, es gibt also auch „versteckte“ unds und oders. Durch syntaktische 
Umformung der Attribute in Relativsätze kann man diese wieder hervorholen, vgl. „eine langwierige, gewöhnlich lebensbedrohende Krankheit $\rightarrow$ eine Krankheit, die langwierig und gewöhnlich lebensbedrohend ist“. Der Nachteil dieses Vorgehens liegt aber auf der Hand: Die sprachliche Formulierung verliert an Übersichtlichkeit, sie wird schwerfällig, enthält stilistisch als anstößig geltende Wiederholungen und widerspricht somit der häufig erhobenen Forderung nach größerer Eleganz von Rechtstexten. Damit nicht genug: Beileibe nicht jedes Attribut lässt sich in eine Prädikation mit Kopula umwandeln, vgl. im vorliegenden Fall dt. * „eine Krankheit, die schwer ist“. Häufig ist man also zu einem faulen Kompromiss verdammt, der weder der Forderung nach maximaler Transparenz noch jener nach einer stilistisch untadeligen, prägnanten Formulierung gerecht zu werden vermag.

Unser nächstes Beispiel entstammt wiederum der polnischen Gesetzgebung und hat nochmals mit einem fehlenden Komma zu tun. Das Verfassungsgericht befand den folgenden Passus 1997 für verfassungswidrig6:

(2) Prawo do życia podlega ochronie, w tym również w fazie prenatalnej w granicach określonych w ustawie, [...].

(Das Recht auf Leben unterliegt dem Schutz auch in der pränatalen Phase innerhalb der im Gesetz bestimmten Grenzen, [...].)

Die Argumentation lautete, dass damit das durch die Verfassung geschützte Recht auf Leben ins Belieben der untergeordneten Instanz (des Gesetzgebers) gestellt worden sei. Der Mangel könne geheilt werden durch ein Komma vor „w granicach [...]“. Während die erste Aussage nachvollziehbar ist, gilt dies kaum für die zweite: Wird die ganze Ergänzung „w tym również w fazie prenatalnej“ jetzt als Parenthese gefasst, so rückt das ganze Recht auf Leben in den Geltungsbereich der Bestimmung ,innerhalb der im Gesetz bestimmten Grenzen', was kaum den höchstrichterlichen Intentionen entsprochen haben dürfte.

Unser nächstes Problem hat mit dem Konnektor selber zu tun. Es hat diesem Beitrag zu seinem Titel verholfen: Leider ist ein und nicht immer ein und, sondern in Wirklichkeit ein oder und vice versa. Dies sei zunächst anhand der alltagssprachlichen Verhältnisse illustriert:

(3) At the conference dinner tonight, you can have stuffed artichoke with asparagus and also lamb chops with mashed potatoes.

(4) Would you like olives, or pretzels, or crisps, or beer or anything?7

6 Gazeta Wyborcza, 26.02.2007.

7 Beide Beispiele sind nach C. Vogel: Law matters, 27 zitiert. 
Für jeden routinierten Tagungsbesucher dürfte klar sein, dass er in (3) nicht zum Genuss von sowohl vegetarischem als auch Fleischmenü eingeladen wird, sondern lediglich zu einem der beiden. Umgekehrt wird der in (4) angesprochene Partygänger die Äußerung nicht unbedingt als Aufzählung strikter Alternativen verstehen, sondern je nach Gusto auch als ,sowohl als auch'- Angebot von jeweils zwei oder mehr Snacks. Die paarweise alternative Lesung lässt sich allerdings erreichen durch eine entsprechende Prosodie mit Betonung des Erstkonjunkts: „[...] ólives or pretzels?“ Andererseits erzwingt das nächste Beispiel eine strikte und-Interpretation:

(5a) You must not smoke or eat in the library.

(5b) You must not smoke and you must not eat in the library.

Eine Übersetzung von (3)-(5) ins Deutsche oder Russische zeigt, dass dort dieselben Verhältnisse herrschen, d.h., die Opposition von und vs. oder scheint ebenfalls vertauscht bzw. aufgehoben. Andererseits gibt es genügend Kontexte, wo keine Vertauschbarkeit der beiden Konnektoren denkbar wäre, vgl. „I would like olives or pretzels“ $\neq$ „I would like olives and pretzels“ oder aber „Die Wurst liegt sicher auf dem Tisch oder im Kühlschrank“. Wodurch ist also das abweichende Verhalten von (3)-(5) bedingt? In den ersten beiden Fällen scheint der Sprechakt ,Angebot' dafür verantwortlich zu sein: Seitens des Anbieters handelt es sich sowohl um eine und-Verknüpfung der Art „vorrätig

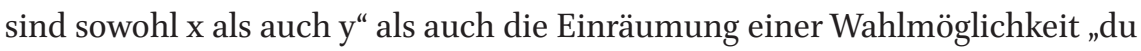
kannst x oder y haben“, wobei die Wahl zwischen der inklusiven Interpretation in (4) und der exklusiven in (3) durch allgemeine kulturell bedingte Skripte der Art „mehrere Snacks möglich“ vs. „nur ein Hauptgang erlaubt“ gesteuert wird. (5) hingegen folgt wieder einem logischen Gesetz (genauer: einem der beiden De Morgan'schen Gesetze), dessen Wirkung durch Klammerung verdeutlicht werden kann: not (smoke or eat) kann „ausmultizipliert“ werden als (not smoke) and (not eat). Gemeinsam ist allen Beispielen die Kann-Modalität (in 5 in verneinter Form). Genau diese aber liegt nach Sannikov der Bedeutung von russ. ili zugrunde: $X$ ili $Y=v$ kačestve opisyvaemogo vozmožen $X$, vozmožen $Y$, wobei diese Formulierung auch die inklusive Lesung „oder beide“ nicht ausschließt. ${ }^{8}$ Diese Analyse betrifft wiederum nicht nur die Einzelsprache Russisch, sondern lässt sich analog für die oder-Verknüpfung in andern Sprachen formulieren.

8 V.Z. Sannikov: Kon"junkcija i dis"junkcija, 59. Zur Diskussion um inklusive und exklusive Lesung von ili in der russischen Fachliteratur ausführlicher H. Kuße: Konjunktionale Koordination, 223-231. 
Unsere Beispiele haben auch klar gemacht, dass die alltagssprachliche vermeintliche Unschärfe sehr wohl auch für Rechtstexte relevant sein dürfte, die ja ebenfalls als Kann- oder Muss-Vorschriften (vgl. Bsp. (5)) konzipiert sind. Der folgende Passus aus der irischen Verfassung beleuchtet das Problem schlagartig: ${ }^{9}$

\section{(6) Article 4}

The name of the state is Eire, o, in the English language, Ireland.

Art. 8 stipuliert zusätzlich:

(7) 1. The Irish language as the national language is the first official language.

2. The English language is recognised as a second official language.

Nun stört in (6) schon wieder das oder, v.a. auch im Verbund mit der doppeldeutigen Interpunktion: In Wirklichkeit ist ja die Bezeichnung Ireland in der 2. Staatssprache alles andere als optional, sondern zwingend. Die korrekte Formulierung von (6) müsste also lauten:

(6') The name of the state in the national language is „Eire“, AND the name of the state in the other official language is "Ireland".

Dies ist auch die eine mögliche Lesung, ja vielleicht sogar die defaultInterpretation, von (6), aber eben nicht die einzig mögliche. Das Bewusstsein dieser Quelle von Fehldeutungen ist offenbar in der angelsächsischen Rechtssprechung bereits derart verankert, dass mancherorts eine entsprechende Interpretationsregel gilt: „[... the ,and/or' rule, which is that in some jurisdictions (e.g. New York), an interpretation statute specifies that the two words may be used interchangeably."10 Damit kapituliert das Recht vor den Tücken der Alltagssprache, ohne dass eine sinnvolle Regulierung der juristischen Fachsprache erwogen würde.

Angesichts des Bisherigen wäre es wohl naiv anzunehmen, dass die russische Gesetzgebung vor ähnlichen Unklarheiten gefeit ist. Ein diesbezüglich sensibles Begriffspaar stellt čest' $i$ dostoinstvo dar, das uns in Kap. II ausführlich beschäftigen wird. Die zivilrechtliche Bestimmung in Art. $15^{2}$ des Graždanskij kodeks lautet z.B.

9 C. Vogel: Law matters, 33, 4of.

10 Ebd., $26 f$. 
(8) Защита чести, достоинства и деловой репутации

1. Гражданин вправе требовать по суду опровержения порочащих его честь, достоинство или деловую репутацию сведений, если распространивший такие сведения не докажет, что они соответствуют действительности.

По требованию заинтересованных лиц допускается защита чести $\boldsymbol{u}$ достоинства гражданина и после его смерти.

Hier findet sich zweimal die dreifache Aufzählung von Ehre, Würde und geschäftlichem Ansehen; dabei gibt jeweils das letzte Glied darüber Aufschluss, welcher Verknüpfungsgehalt der ganzen Aufzählung zugrunde liegt: Im Titel ist dies und, im ersten Absatz dann aber oder. Der zweite Absatz enthält kein Tripel mehr, sondern nur noch das Paar Ehre und Würde; der Konnektor lautet diesmal wieder und. Nun kann man argumentieren, dass der Titel mehr eine Art Übersicht über die vorkommenden Tatbestände liefert und daher das summierende und so zu motivieren sei; ${ }^{11}$ dann bleibt aber immer noch der Widerspruch zwischen dem 1. und dem 2. Absatz. Die strafrechtliche Bestimmung der Verleumdung bietet nochmals eine neue Variante, die beide Konnektoren kombiniert:

\section{(9) Статья 129 УК РФ. Клевета}

Клевета, то есть распространение заведомо ложных сведений, порочащих честь и достоинство другого лица или подрывающих его репутацию,[...].

Ehre und Würde sind also jetzt untereinander enger, nämlich im Sinne der logischen Konjunktion verbunden, von beiden als Alternative abgesetzt ist das Ansehen (hier fällt das Fehlen des Attributs geschäftlich auf, vgl. die zivilrechtliche Formulierung in Bsp. (8)). Die Syntax diktiert hier für einmal eine eindeutige Hierarchisierung der beteiligten Begriffe, die zugehörige Klammerung wäre

(9') сведений, (порочащих (честь $и$ достоинство) другого лица) или (подрывающих его репутацию).

Die und-Konnexion ist hier wirklich fix: Die Wortverbindung zaščita česti $i$ dostoinstva liefert bei Google 8150 Treffer (12.11.2011), zaščita česti ili dostoinstva

11 Damit würde diese Übersicht eine vergleichbare Semantik aufweisen wie die Angebote in Bsp. (3) und (4). 
genau einen. Darüber hinaus ist auch die Abfolge der Konjunkte fest, denn zaščita dostoinstva $i$ čest $i$ ist ganze 21 Mal vertreten, die oder-Variante überhaupt nicht. Und schließlich begegnet auch zaščita dostoinstva allein nur 926mal. Ersetzungs-, Umstellungs- und Weglassprobe erweisen also ein hohes Ausmaß an phraseologischer Bindung des ganzen Ausdrucks zaščita česti i dostoinstva: Hier hat die Rechtssprache sich auch in der Allgemeinsprache durchgesetzt.

Zu guter Letzt sei noch auf die Sammelüberschrift für alle einschlägigen Bestimmungen des Strafgesetzbuchs verwiesen. Sie enthält ein neues Begriffstripel, denn diesmal ist die Freiheitsberaubung mit von der Partie:

(10) Преступления против свободы, чести $и$ достоинства личности

Es lohnt sich, auch die Liste der darunter fallenden Straftatbestände zu konsultieren:

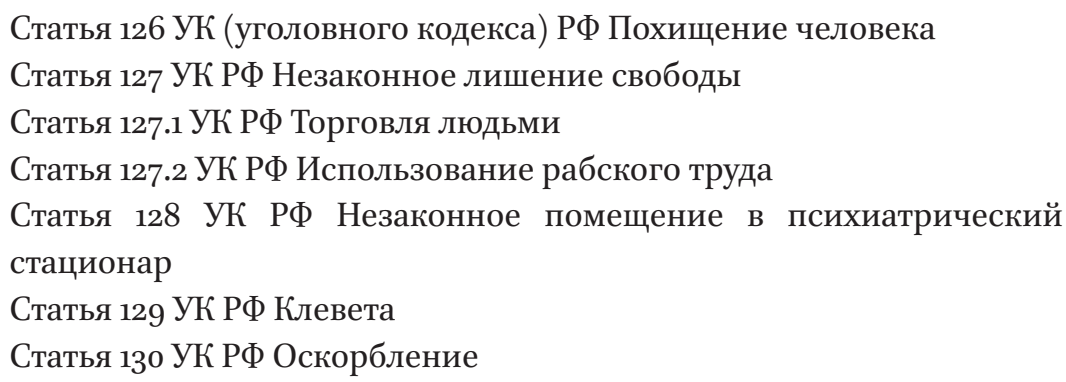

Bei der Durchsicht fällt sofort auf, dass die Freiheitsberaubung nur in den ersten fünf aufgeführten Tatbeständen involviert ist, hingegen nicht in Art. 129 (Verleumdung) und 130 (Beschimpfung). M.a.W.: Auch hier erweist sich der und-Konnektor als irreführend, die korrekte Formulierung hätte stattdessen gelautet:

(10') Преступления против свободы или чести $u$ достоинства личности,

wobei allerdings hier die Klammerung noch offen bleibt - es gibt keine sprachliche Regel, wonach die und-Verknüpfung Vorrang vor der oder-Verknüpfung hätte, d.h., im Prinzip wäre auch die Lesung als против ((свободы или чести) и достоинства) möglich.

Nebenbei hat sich erwiesen, dass die asyndetische Aufzählung, die uns schon in Zusammenhang mit Bsp. (1) beschäftigte, offenbar nicht nur eine Auflösung mithilfe des expliziten und kennt, sondern womöglich auch eine 
im Sinne von alternativem oder. Tatsächlich erfordert gerade dieser Punkt die besondere Aufmerksamkeit des Laien: Sehr häufig enthalten juridische Texte vertikal angeordneten Auflistungen, ohne dass beim letzten Glied ein expliziter Konnektor auftritt, der die interne Verknüpfungssemantik (und? oder?) markieren würde. Im folgenden Vertragsentwurf (es geht um ein Austauschabkommen mit der Universität St. Petersburg) ist die vertikal angeordnete Aufzählung eindeutig als und-Konjunktion zu verstehen:

(11) 2.3. Университет обязуется:

2.3.1. Организовать прием и зачисление студентов (стажеров) Заказчика в соответствии с Правилами приема и обучения в СПбГУ на договорной основе.

2.3.2. При успешном выполнении учебного плана выдать студенту (стажеру) сертификат установленного образца.

2.3.3. Организовать встречу студентов (стажеров) в СанктПетербурге и их доставку в аэропорт (или на вокзал) после окончания курса обучения.

2.3.4. Оказывать студенту (стажеру) содействие в получении въездных и выездных виз для следования в Россию и выезда на родину.

2.3.5. Оказывать студенту (стажеру) содействие в размещении в студенческом общежитии или в семье.

2.3.6. Университет имеет право требовать от Заказчика возмещения понесенных материальных убытков, если таковые были вызваны нарушением Заказчиком условий настоящего Соглашения и наоборот.

In diesem Fragment stellt im Übrigen eine weitere Interpunktion ein Interpretationsproblem dar: Wie ist die Klammer in student (stažer) aufzulösen? Im Prinzip kommen hier zwei mögliche Deutungen in Frage, nämlich nochmals das disjunktive oder vs. Referenzidentität im Sinne einer Reformulierung (vgl. dt. oder anders), d.h. entweder student ili stažer oder aber student = stažer. Im gegebenen Fall fällt die Entscheidung zugunsten der ersten Interpretation aus, da die beiden Begriffe student und stažer in der russischen universitären Terminologie einen unterschiedlichen Status bezeichnen.

Die kumulative Deutung solcher vertikal entwickelter Listen im Sinne des logischen und gilt freilich beileibe nicht immer, wie unser nächstes Beispiel deutlich macht. Art. 173 des schweizerischen StGB (Üble Nachrede) legt fest: 
(12) Wer jemanden bei einem andern eines unehrenhaften Verhaltens oder anderer Tatsachen, die geeignet sind, seinen Ruf zu schädigen, beschuldigt oder verdächtigt, wer eine solche Beschuldigung oder Verdächtigung weiterverbreitet, wird, auf Antrag, mit Gefängnis bis zu sechs Monaten oder mit Busse bestraft.

Der gesunde Menschenverstand legt nahe, dass die beiden mit Wer ... eingeleiteten Bedingungen nicht kumulativ, sondern alternativ gelten. Nachdem aber beide Bedingungen auch interne, explizit mit oder markierte Alternativen enthalten, könnte dies bei einem Laien für Verwirrung sorgen: Warum einmal ein explizites, ein andermal ein implizites oder? Rein logisch betrachtet ist die typographische Hierarchisierung auch überflüssig: Eine Kette von disjunktiv verknüpften Aussagen der Art $p \vee q \vee r \vee s$... bedarf keiner Klammerung, da die Disjunktion ohnehin assoziativ ist, d.h., es gilt: $(p \vee q) \vee r=p \vee(q \vee r)$. Hier ist jedoch anzumerken, dass das sprachliche Design dieses ganzen Gesetzeswerks einheitlich mit solchen alternativ angeordneten Wer ...-Bedingungen arbeitet; eine Fehlinterpretation im vorliegenden Fall dürfte damit ausgeschlossen sein.

Die Syntax der Koordination hält noch eine andere Quelle von Ambiguität bereit, die in juridischen Texten vermieden werden müsste. Wenn die Konjunkte nicht Satzformat aufweisen, sondern aus Nominalgruppen mit zusätzlichem Attribut bestehen, kann folgende Situation eintreten: In russ. starye baby i mužiki kann sich das Attribut sowohl auf die ganze koordinierte Nominalphrase als auch bloß auf ihr Erstglied beziehen, also:

(13) (Starye baby) i mužiki $\quad \neq \quad$ Starye (baby i mužiki).

Dass solche Doppeldeutigkeiten auch in Rechtstexten vorkommen, illustriert das nächste, aus Solan, The language stammende Beispiel:

(14) The possibility of admission is available to girls and boys under six years of age.

Wie aus dem Vergleich mit (13) ersichtlich, hat die Stellung des Attributs (präoder postnominal) hierbei keine Bedeutung. Im sprachlichen Alltag spielen solche ambigen Strukturen eine nicht unbedeutende Rolle, auch wenn sie meist unbemerkt bleiben. So offeriert ein Institut in seinem TV-Werbespot „Partnervermittlung für Akademiker und Singles mit Niveau“: Hier können sich die Akademiker aussuchen, ob sie sich mit oder ohne Niveau auf Partnersuche begeben wollen. 
Die koordinative Verknüpfung zeitigt auch einen semantischen Effekt, der juristisch relevant werden kann. Er soll anhand des folgenden scherzhaft gemeinten Warnschilds demonstriert werden:

(15)

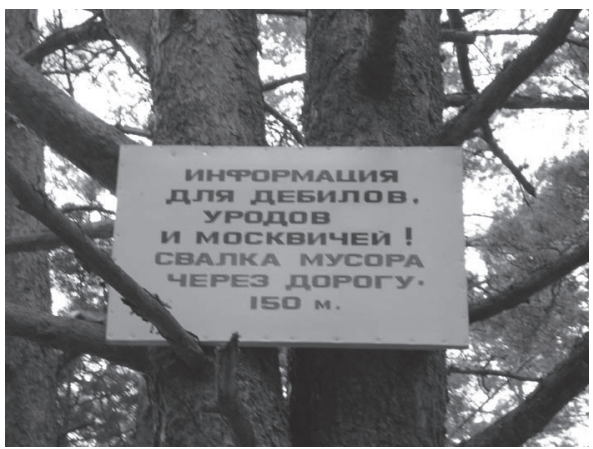

Scherzplakat gegen illegales littering Abbildungsnachweis: http://www.korova.ru/ humor/viewer.php?id=2822\&types=p\&subtypes= russ

Nach E. Lang ${ }^{12}$ wird durch jede koordinierte Struktur eine sogenannte Gemeinsame Einordnungsinstanz (GEI) erzeugt, d.h. eine Art kleinster gemeinsamer semantischer Nenner. Im vorliegende Fall müssten also debily, urody und moskviči eine solche GEI aktivieren. Nachdem die ersten beiden Terme eindeutig beleidigenden Charakter haben, würde somit auch der dritte Term eine abschätzige Wertung ausdrücken.

An dieser Stelle sei ein kurzer Exkurs in die forensische Linguistik gestattet. Die Frage, die sich hier aufdrängt, lautet: Könnte ein Moskauer aufgrund dieses corpus delicti z.N. auf Beschimpfung bzw. oskorblenie (§ $130 \mathrm{UK}$ ) klagen? Dafür, dass dies ein aussichtloses Unterfangen wäre, sprechen drei gute Gründe. Der erste hat mit der genannten GEI zu tun: Wenn eine Information nicht explizit ausgedrückt wird, wird nach der Praxis der russischen (und wohl nicht nur ihrer) Rechtssprechung die eindeutige Rekonstruierbarkeit des Weggelassenen gefordert. Diese wäre z.B. im Falle einer Ellipse per definitionem gegeben, nicht aber im vorliegenden Beispiel, da aus debily, urody und moskviči bestenfalls so etwas wie ,Abweichung von der intellektuellen bzw. moralischen Norm‘ o.ä. abgeleitet werden kann. Der zweite Grund hat mit dem Referenztyp der drei Terme zu tun: Diese beziehen sich hier auf offene Klassen von Individuen, d.h., sie weisen generische Referenz auf. Dieser Fall ist aber in 
vielen Rechtssystemen nicht strafwürdig: So ging der Träger eines T-Shirts mit der Aufschrift A.C.A.B (= „All cops are bastards“) vor dem Stuttgarter Landgericht straffrei aus, weil diese Aufschift als „nicht beleidigungsfähig“ erkannt wurde: Man kann nicht beliebige Polizisten auf der ganzen Welt beschimpfen. Ähnlich begründet wurde vermutlich auch vom deutschen Bundesgerichtshof der Freispruch des Angeklagten, der „Soldaten sind Mörder“ geäußert hatte. Entsprechend können die Moskauer als offene Klasse nicht zum Objekt einer kollektiven Beschimpfung werden. ${ }^{13}$ Und schließlich lautet drittens der Wortlaut von Art. 130 UK: „Oskorblenie, to est' umyšlennoe uniženie česti i dostoinstva ličnosti, vyražennoe v nepriličnoj forme, [...].“ Im vorliegenden Fall erfüllt keines der drei Nomina diese zusätzliche Bedingung der nepriličnaja forma (s.u., Kap. II).

Nach dieser kleinen forensischen Digression sei noch kurz auf einen dritten Konnektor eingegangen, dem in Rechtstexten keine geringere Bedeutung zukommt als und bzw. oder: die wenn-dann-Verknüpfung. Ihre „kanonische“ Form wäre diejenige eines Bedingungssatzes des Typs Wenn jemand $X$ begeht ..., doch schon Bsp. (12) hatte ein mögliches Substitut illustriert, nämlich verallgemeinernde Relativsätze der Art Wer $x$ begeht ... Die Kombination beider Varianten hilft stilistisch störende Wiederholungen zu vermeiden, vgl. Art. 115 aus dem Schweizerischen Strafgesetzbuch: „Wer aus selbstsüchtigen Beweggründen jemanden zum Selbstmorde verleitet oder ihm dazu Hilfe leistet, wird, wenn der Selbstmord ausgeführt oder versucht wurde, [...].“

Daneben existieren aber auch präpostionale Ausdrücke mit konditionaler Semantik: So enthält der in Bsp. (11) partiell wiedergegebene Vertragsentwurf die Formulierung

(15) Студент (стажер) имеет право прервать обучение в случае невозможности его продолжения по обоснованой причине.

Eine weitere Variante stellt der kombinierte Konnektor $v$ slučae esli dar, der ebenfalls in Rechtstexten zu belegen ist; das dt. Äquivalent wäre falls. Schließlich existiert auch eine implizite Variante: Die Präposition pri kann ähnlich wie dt. bei je nach Kontext statt der primären, räumlichen eine temporale, konzessive oder eben konditionale Geltung annehmen. Trotz dieser potentiell mehrdeutigen (oder vagen) Bedeutung findet gerade dieser Marker häufig Anwendung in Rechtstexten, vgl. aus Bsp. (11):

13 Auszunehmen davon sind natürlich rassistische und andere diskriminierende Beschimpfungen aufgrund von Hautfarbe, Religion etc. Im Strafgesetzbuch der Russischen Föderation wird dieser Fall in UK st. 282 (Razžiganie mežnacional'noj rozni) geregelt. 
(11') При успешном выполнении учебного плана выдать студенту (стажеру) сертификат установленного образа.

Gibt es auch eine asyndetische, d.h. Null-Variante des konditionalen Verhältnisses? In deutschsprachigen Rechtstexten ist die Asyndese durchaus geläufig; sie erfordert dann eine sonst für Entscheidungsfragen charakteristische Inversion von Subjekt und Hauptverb, vgl. Art. $70^{3}$ des schweizerischen StGB:

(16) Ist vor Ablauf der Verjährungsfrist ein erstinstanzliches Urteil ergangen, so tritt die Verjährung nicht mehr ein.

Immerhin fungiert dann im Nachsatz der Konnektor so als Platzhalter des fehlenden wenn. In der russischen Umgangssprache ist dieselbe asyndetischkonditionale Konstruktion mit Inversion geläufig und lässt sogar drei Modi Indikativ, Konditional oder Imperativ - im Bedingungssatz zu, vgl. Pridi on vovremja, ... / prišel by on vovremja, ... oder Vspomnju, skažu, doch ist keines dieser Verfahren in der Rechtssprache zulässig.

Summa summarum zeigt sich also, dass der Ausdruck von Bedingungen in der juridischen Fachsprache überhaupt nicht reguliert ist und entsprechend dieselbe Bandbreite an Varianz zulässt wie die formellen Register der Alltagssprache. Im Falle des Deutschen ergeben sich aus der obigen Übersicht zumindest vier finitverbale Realisierungen (mit wenn, falls, verallgemeinerndem Relativsatz mit wer oder asyndetisch), daneben zwei präpositionale; in russischen Rechtstexten entfällt hiervon einzig die Asyndese wegen ihrer anderen stilistischen Polung. Diese größere Varianz unterscheidet Bedingungssätze als ungefähres Pendant der logischen Implikation vom Ausdruck der logischen Konjunktion und Disjunktion. Sie führt aber kaum je zu Missverständnissen, es entsteht hier also anders als bei und sowie oder kein sprachlicher Regulierungsbedarf im Sinne einer größeren Vereinheitlichung der verwendeten Ausdrucksmittel.

Unser letztes Fallbeispiel hat nichts mehr mit Konnektoren zu tun, sondern beleuchtet nochmals die mitunter fatalen Folgen mangelnder Explizitheit durch Weglassung unverzichtbarer Informationen. Das irische Scheidungsrecht ist einerseits durch die Verfassung, andererseits durch die Family Law (Divorce) Act von 1996 geregelt. Der Verfassungsartikel besagt:

(17) Art. $41 \S 3(2)$

A court designated by law may grant of a dissolution of marriage where, but only where, it is satisfied that - 
(i) at the date of the institution of the proceedings, the spouses have lived apart from one another for a period of, or periods amounting to, at least four years during the previous five years, (ii) [...].

Wie C. Vogel ${ }^{14}$ ausführt, könnte bei einer buchstabengetreuen Auslegung dieser Bestimmung ein Paar im Prinzip gleich am Tag nach der Hochzeit schon die Scheidung einreichen, weil das zeitliche Intervall "during the previous five years" keinen Bezug auf das Datum der Eheschließung (previous to what?) enthält und auch die Formulierung live apart keineswegs synonym mit dem juristisch relevanten be separated ist. Auch der o.e. Family Law Act bringt hier keine Klarheit: „A popular predilection seems to assume that this reckoning commences with the start of the marriage; however, there is no such provision in the text of the constitution or the relevant Act." ${ }^{\text {"5 }}$ Es sei hervorgehoben, dass auch der Passus "the spouses have lived apart from one another" die gewünschte Interpretation nicht präzisiert, denn spouses referiert hier auf den Zeitpunkt, der mit "at the date of the institution of the proceedings" umschrieben wird. Dies sei mit einem analogen Beispiel verdeutlicht: „Präsident Putin stammt aus ärmlichen Verhältnissen“ setzt auch nicht voraus, dass Putin schon in seiner Kindheit das Präsidentenamt innehatte, sondern bezieht sich auf den Sprechzeitpunkt: „der gegenwärtige Präsident“ (also bis und mit 2019).

Häufig werden solche Grauzonen, wo neben einer default-Interpretation auch eine andere Interpretation zulässig bleibt, in der politischen Propaganda ausgenutzt. So warb die rechtspopulistische SVP im Kanton Zürich bei den letzten kantonalen Wahlen mit einem Flyer mit folgendem Wortlaut: „Nehmen Sie die graue Liste o1 Schweizerische Volkspartei (SVP). Alle restlichen Listen können sie wegwerfen, weil sonst ihre Wahl ungültig ist." Gewiss werden die allermeisten Wähler dies so interpretieren, dass sonst den Fall ausschließen soll, dass der Wähler zwei Listen einwirft, aber die Lesung, wonach überhaupt nur die SVP-Liste zu einer gültigen Wahl verhilft, wird eben nicht ausgeschlossen. Außerdem lässt sich hier nicht argumentieren, dass die default-Lesung einfach vom gesunden Menschenverstand bzw. dem Skript „Demokratische Wahlen in einem Mehrparteiensystem“ diktiert werde: Diese beiden Instanzen lassen die gesamte Werbung als höchst überflüssig erscheinen.

Im Sinne einer Zwischenbilanz zu diesem Kapitel lässt sich Folgendes formulieren: Wie unsere Beispiele aus dem polnischen, russischen, irischen und schweizerischen Kontext erwiesen, lässt die rechtssprachliche Syntax

\footnotetext{
14 C. Vogel: Law matters, $45 \mathrm{ff}$.

15 Ebd., 47.
} 
im Verhältnis zur alltagssprachlichen Syntax kaum ein höheres Maß an Regulierung im Sinne einer verstärkten Explizitheit erkennen. Dies gilt insbesondere in Fällen von doppeldeutiger Konnexion (und vs. oder?) mit overtem Konnektor ebenso wie bei asyndetischem Anschluss, aber auch von sinnstörenden Weglassungen wie im letzten Textbeispiel aus dem irischen Scheidungsrecht. Im Falle des russischen Graždanskij kodeks schreckt der Gesetzgeber auch nicht vor eklatanten Inkonsistenzen zurück, vgl. Bsp. (8); ebenso wenig stört offenbar die anderslautende Sprachregelung im Ugolovnyj kodeks (Bsp. (9)). Hier drängt sich die Frage nach den Gründen für diese mangelnde Redaktionsarbeit auf: Fehlt etwa das nötige Problembewusstsein? Ein Blick in die angelsächsische Spezialliteratur macht klar, dass dies zumindest in diesem Sprachraum nicht zutrifft. Mangelt es an kompetenten Instanzen für eine sinnvollere Regulierung? Und inwieweit werden Linguisten bei der Ausarbeitung von Gesetzestexten herangezogen? Diesbezüglich divergiert das Bild in den einzelnen nationalen Gesetzgebungen erheblich. So beklagt etwa Irina Levontina, dass bei der Neufassung des russischen Strafgesetzbuches keine linguistischen Sachverständigen herangezogen wurden. Ihr Urteil fällt äußerst ernüchternd aus: ${ }^{16}$

(18) И разве лингвист виноват, что законодатель именно так определил понятие оскорбления? Пригласил бы его, лингвиста, когда обсуждалась новая редакция УК! Лингвист сказал бы ему, что очень легко переформулировать экспликацию слова оскорбление так, чтобы под нее подпадало то, что произнес Киркоров. [...] Нормы закона формулируются небрежно. Лингвисты к оценке формулировок, насколько я знаю, не привлекаются. А ведь чем более туманно и неоднозначно написаны законы, тем больше простора для произвола и коррупции.

Auch wenn die Verfasserin hier die definitorisch-lexikalische Abfassung von Gesetzestexten im Auge hat, gilt ihr Verdikt gewiss nicht minder für deren syntaktische Ausarbeitung.

Im deutschen Sprachraum liegen die Verhältnisse nicht so desolat. So verfügt in der BRD seit über 40 Jahren die Gesellschaft für deutsche Sprache über den Redaktionsstab beim Deutschen Bundestag über ein Mitgestaltungsrecht ${ }^{17}$. Trotzdem „kam diesem Redaktionsstab in der Vergangenheit kaum

16 I.B. Levontina: Bukva i zakon (online-Ausgabe).

17 S. Thieme, G. Raff, K. Tacke: Möglichkeiten, 161. 
mehr als eine Alibifunktion zu". ${ }^{18}$ In der Schweiz ist seit mehr als 30 Jahren der Zentrale Sprachdienst der Bundeskanzlei für verständliche Gesetze in den drei Staatssprachen (ohne Rätoromanisch) verantwortlich, und seine Mitarbeiter(innen) sind als Mitglieder der Redaktionskommission von Anfang an in den Gesetzgebungsprozess eingebunden. ${ }^{19}$ Dieses Erfolgsmodell diente als Muster für die Einrichtung eines Redaktionsstabs Rechtssprache beim Berliner Justizministerium, in dem seit dem 01.04.2009 sieben Linguist(inn)en Entwürfe zu Gesetzen und Verordnungen mit bearbeiten. Der Beschreibung 20 nach zu schließen, kommt es dabei auch zu syntaktischen Verbesserungen; sie betreffen z.B. überlange Ketten von Genitivattributen und Relativsätzen, Fälle wie die bisher in diesem Beitrag diskutierten werden jedoch nicht genannt.

\section{Zur Begrifflichkeit der Rechtssprache: doppeldeutig, vag oder weitgespannt?}

Im Gegensatz zur rechtssprachlichen Syntax ist die juristische Begrifflichkeit ein oft beackertes Feld. Deshalb seien hier nur die fundamentalsten Fakten in Erinnerung gerufen. Die gegenwärtige Gesetzessprache ist zwar keine reine Fachsprache, sondern oszilliert innerhalb L. Hoffmanns Schichtenmodell zwischen der Stufe der angewandten Wissenschaften mit hohem Abstraktionsgrad und sehr hohem Anteil an Fachterminologie und der Stufe der Sprache der materiellen Produktion mit entsprechend niedrigerer Ausprägung dieser beiden Komponenten. ${ }^{21}$ Dennoch gilt damit: Auch als partielle Fachsprache gehört die juridische Sprache zu den Soziolekten, somit unterscheidet sie wie andere Fachsprachen auch von den übrigen Soziolekten wie z.B. Argots, Jargons oder Slangs vor allem zweierlei, nämlich ihr hoher Normierungsgrad und ihr uneingeschränktes Sozialprestige (d.h., sie verfügt nicht nur in der Ingroup, sondern in der gesamten Gesellschaft über die nötige Akzeptanz). Als Besonderheit juridischer Terminologien im Vergleich mit anderen Fachbzw. wissenschaftlichen Terminologien ist ihre nationale Normierung festzuhalten: Dies gilt selbstredend nicht nur für die angelsächsische Welt, sondern auch für Deutschland, Österreich und die Schweiz, ebenso wohl für die russische ${ }^{22}$ und die weißrussische juridische Fachsprache. Z.T. hängt dies

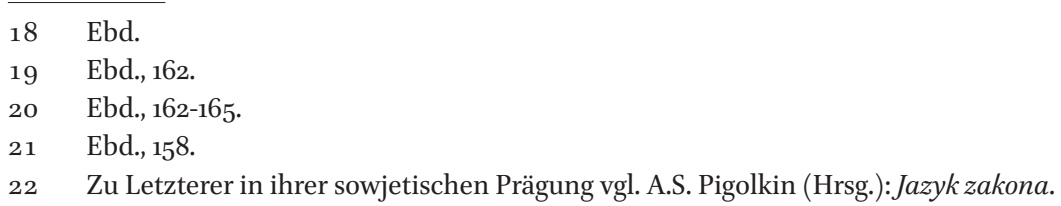


mit der national divergierenden Systematik der Sachverhalte bzw. Straftatbestände zusammen: So kennt das schweizerische Strafrecht ein Tötungsdelikt mehr als das deutsche, und die deutsche und schweizerische Unterscheidung von Verleumdung und übler Nachrede (vgl. Bsp. (12)) ist den meisten andern Rechtsordnungen, so insbesondere dem Ugolovnyj kodeks der Russischen Föderation, unbekannt. Zwei weitere Merkmale juridischer Terminologien sind ihre historische Wandelbarkeit - so kannte das russische vorrevolutionäre Strafrecht noch den Begriff obida anstelle der heutigen oskorblenie, und möglicherweise verschwindet demnächst der Begriff kleveta aus dem russischen Strafrecht, s.u. - und ihre „Semipermeabilität" für die Allgemeinheit: Viele juridische Begriffe haben entweder ein allgemeinsprachliches Pendant oder sind dem Laienpublikum zumindest als fachsprachlicher Import geläufig. Dies führt häufig zu einem der medizinischen Terminologie vergleichbaren Zustand des Halbwissens: Manche Begriffe sind zumindest als signifiant auch dem Laien bekannt, aber er vermag ihnen kein juristisch präzises signifié zuzuordnen. Und schließlich existiert für etliche rechtlich relevante Begriffe überhaupt keine kodifizierte ${ }^{23}$ juristische Definition, sondern nur das allgemein-(standard-)sprachliche Verständnis.

Dies führt auf folgende mit russischen Beispielen illustrierte Dreigliederung:

\begin{tabular}{|l|l|l|}
\hline \multirow{2}{*}{$\begin{array}{l}\text { Nur fachsprachliche } \\
\text { Definition }\end{array}$} & dem Laien geläufig & $\begin{array}{l}\text { isk, istec } \\
\text { sudimost } \\
\text { pokazanie }\end{array}$ \\
\cline { 2 - 3 } & dem Laien i.a. unbekannt & $\begin{array}{l}\text { chiščnie? } \\
\text { otvod sledovatelja }\end{array}$ \\
\hline Fach- vs. allgemeinsprachl. Definition & $\begin{array}{l}\text { oskorblenie } \\
\text { sledstvie } \\
\text { propaganda }\end{array}$ \\
\hline Nur allgemeinsprachl. Definition & $\begin{array}{l}\text { pornografija } \\
\text { obščstvennoe mesto } \\
\text { mat }\end{array}$ \\
\hline
\end{tabular}

a $\mathrm{Zu}$ den Konsequenzen des Fehlens einer allgemein tragfähigen Definition des Mat für die Strafwürdigkeit von dessen Gebrauch auf öffentlichem Grund s. D. Weiss: Umestno li nakazyvat'.

Dabei ist auch klar, dass mit dem Kriterium \pm Zugänglichkeit für Laien bzw. \pm Nähe zur Gemeinsprache in Wirklichkeit nicht eine strikte Dichotomie,

23 Der betreffende Begriff kann trotzdem zum Gegenstand fachinterner Diskussionen werden, z.B. in juristischen Internet-Foren. 
sondern ein Kontinuum mit fließenden Übergängen vorgegeben ist. Noch nicht erfasst ist hier der Sachverhalt der begrifflichen Polysemie, der sowohl innerhalb der Allgemein- als auch der Fachsprache erfüllt sein kann; den letzteren Fall illustrieren die beiden Begriffspaare otvod sledovatelja vs. otvod učastka und zaključenie obvinitelja vs. tjuremnoe zaključenie. Was Begriffe ohne juristische Definition angeht, so liefern hier die drei von A. Baranov diskutierten völlig inkongruenten Definitionen von pornografija ein schlagendes Beispiel für die Unbrauchbarkeit bestehender Wörterbücher für forensische Zwecke. ${ }^{24}$ Und zu guter Letzt hängt die Zugänglichkeit eines juristischen Begriffs ja auch von seiner Position in der fachinternen Differenzierung der Textsorten ab: Vom Grundgesetz, d.h. der nationalen Verfassung, bis hin zu einer Verordnung oder Ausführungsbestimmung ist sprachlich ein weiter Weg, der sich immer mehr von der Gemeinsprache entfernt.

Wo alltagssprachliches und fachsprachliches Verständnis kollidieren, sind Unverständnis oder Unmut beim Laienpublikum vorprogrammiert. Ein brisanter Fall wurde oben unter Bsp. (15) anhand der juristischen Bestimmung von oskorblenie als „umyšlennoe uniženie česti i dostoinstva ličnosti, vyražennoe v nepriličnoj forme“ bereits diskutiert: Das zusätzliche Erfordernis der „unanständigen Form“ lässt den Kreis der nach allgemeinem Rechtsempfinden eigentlich strafwürdigen Äußerungen beträchtlich schrumpfen. ${ }^{25}$ Nicht zu Unrecht schreibt I. Levontina ${ }^{26}$ (s. Bsp. (18)) dazu:

(19) А что до оскорбления, то не все, что звучит оскорбительно с точки зрения русского языка, является оскорблением в соответствии с той же ст. 130 УК. Если меня спросят: „Ты диссертацию сама писала или нанимала кого-нибудь? - я сочту такой вопрос оскорбительным, но не уголовно наказуемым.

In diesem Beitrag geht die Autorin auch auf diejenige cause célèbre ein, die im Zusammenhang mit dem Tatbestand der oskorblenie in den letzten Jahren am meisten Staub aufgewirbelt hat, nämlich auf F. Kirkorovs Invektiven gegen die armenische Journalistin I. Arojan an einer Pressekonferenz im Jahre 2004, die eine Klage wegen Beschimpfung auslösten. Der vom Beklagten als Gerichtsgutachter hinzugezogene A. Baranov kam damals zum Schluss, dass keine der verbalen Entgleisungen Kirkorovs wirklich in allen Punkten den vom

\footnotetext{
24 A. Baranov: Lingvističeskaja èkspertiza, 529-531.

25 Für eine linguistische Definition von oskorblenie vgl. V.Z. Sannikov: Ponjatija, 428-438, zu uniženie (dostoinstva) ebd., 420-425.

26 I.B. Levontina: Bukva i zakon (online-Ausgabe).
} 
Gesetz definierten Tatbestand der oskorblenie erfüllte. ${ }^{27}$ Dieses Gutachten wurde zwar vom Gericht selbst gar nicht als Beweismittel berücksichtigt, hingegen löste es einen landesweiten Proteststurm aus - wie konnte ein Angehöriger der Akademie der Wissenschaften öffentlich dafür eintreten, die öffentliche Beleidigung einer jungen Frau mit Mat-Ausdrücken sei als nicht strafwürdig anzusehen? „Ekspert: Kirkorov ničego osobennogo ne skazal“; „Igry skvernoslovov. O chamstve v kontekste vysokoj lingvistiki“; „Institut RAN ,izobrel' dlja Kirkorova special'nye normy russkogo jazyka“28 lauteten einige der empörten Schlagzeilen. Sogar am eigenen Institut gab es Bestrebungen, den unbequemen Kollegen wegen dieses einen Gutachtens zu entlassen. In Wirklichkeit hatte er lediglich versucht, dem Wortlaut von Artikel 130 UK gerecht zu werden.

Im Hinblick auf die im ersten Kapitel aufgegriffenen Ehrverletzungsdelikte wird im Folgenden auf die Schlüsselbegriffe Ehre, Ansehen und Ruf eingegangen. Hier verdient zunächst die Absenz der Ehre im deutschen Strafgesetzbuch Aufmerksamkeit: Zur Illustration sei hier $§ 186$ (Üble Nachrede) angeführt (kursive Hervorhebung von mir, D.W.): ${ }^{29}$

(19) Wer in Beziehung auf einen anderen eine Tatsache behauptet oder verbreitet, welche denselben verächtlich zu machen oder in der öffentlichen Meinung herabzuwürdigen geeignet ist, wird, wenn nicht diese Tatsache erweislich wahr ist, mit Freiheitsstrafe bis zu einem Jahr oder mit Geldstrafe und, wenn die Tat öffentlich oder durch Verbreiten von Schriften ( 11 Abs. 3) begangen ist, mit Freiheitsstrafe bis zu zwei Jahren oder mit Geldstrafe bestraft.

(lawww.de/Library/stgb/185.htm)

Auch im schweizerischen Straf- und Zivilrecht fällt der sparsame Umgang mit dem Schlüsselbegriff Ehre auf. Dieser kommt z.B. bei Übler Nachrede (Art. 173, s.o. Bsp. (12)) und Verleumdung (Art. 174) gar nicht mehr vor, dort ist nur noch von unehrenhaftem Verhalten die Rede; erst im Zusammenhang mit der Beschimpfung (Art. 177) findet sich die Formulierung „Wer jemanden [...] in seiner Ehre angreift", außerdem begegnet die Ehre noch in der Überschrift zum ganzen dritten Titel („Strafbare Handlungen gegen die Ehre und den

27 Vgl. http://web.archive.org/web/20040905083226/http://www.7c.ru/Kirkorov/2751.html (Zugriff 01.12.2018) und A. Baranov: Lingvističeskaja èkspertiza, 539-548.

28 Zitiert nach I.B. Levontina: Bukva i zakon (online-Ausgabe).

29 Allerdings scheint in deutschen Kommentaren nach wie vor die Unterscheidung von innerer vs. äußerer Ehre gängig zu sein, vgl. I. Bojani: Ehre, 408. 
Geheim- oder Privatbereich“30) und in Artikel 178, der generell die Verjährung von Vergehen gegen die Ehre regelt. Im Schweizerischen Zivilgesetzbuch ist überhaupt nur noch der Schutz bzw. die widerrechtliche Verletzung der Persönlichkeit vertreten (Art. 28). Diese Zurückhaltung dürfte damit zu tun haben, dass die Ehre als moralischer Wert und als Rechtsgut im deutschen Sprachraum in der jüngeren Geschichte ins Zwielicht, wenn nicht gar in Verruf geraten ist. Dagegen ist sie, wie Bsp. (8)-(9) zeigten, sowohl im russischen Strafwie auch Zivilrecht bestens verankert, und zwar immer in der Doppelung čest' i(li) dostoinstvo. Natürlich stellt sich hier die Frage nach dem semantischen Verhältnis dieser beiden Begriffe, zumal sie ja in der Verbindung zaščita česti $i$ dostoinstva gleichsam als siamesische Zwillinge auftreten (s.o., Kommentar zu Bsp. (9)), ferner deshalb, weil dieses sich bald als und-, bald als oderVerknüpfung präsentiert: Wenn die und-Regel sinnvoll sein soll, dann müssten theoretisch ja Situationen denkbar sein, in denen nur entweder die čest' oder die dostoinstvo verletzt werden können. In einem juristischen Lehrbuch findet sich folgende Definition:

(20) Честь - социально-значимая положительная оценка лица со стороны общественного мнения. Достоинство - самооценка лицом своих моральных, профессиональных и иных качеств. Таким образом, честь является как бы мерилом достоинства гражданина или организации. Деловая репутация - сложившееся общественное мнение о профессиональных достоинствах и недостатках лица (гражданина или организации).

(pravouch.com/.../ist-14--idz-ax255--nf-102.htm)

Dieser Umschreibung zufolge ist russ. čest' der aus dostoinstvo abgeleitete Begriff und wäre wohl am besten mit dt. Ruf zu übersetzen: Es geht um die soziale Geltung des Individuums, s. den Bezug auf die obščestvennoe mnenie (vgl. dazu die öffentliche Meinung im deutschen Strafrecht, s. Bsp. (20)). Störend wirkt sich dann die Polysemie von dostoinstvo aus: In professional'nye dostoinstva fungiert dostoinstva als Antonym zum folgenden nedostatki, also etwa dt. ,Vorzüge'. Im Weiteren wird nach Untertypen differenziert:

(21') Сфера отношений, формирующих понятие чести и достоинства гражданина, несколько шире, чем формирующие признаки чести и достоинства юридического лица. Так, существует понятие

30 Wiederum ist das und in dieser Überschrift wohl einfach summierend zu deuten, ähnlich wie bei Bsp. (8) und (10). 
человеческого, национального, профессионального, женского и мужского достоинства личности.

Nebenbei erfährt man hier, dass auch juristische Personen über Ehre und Würde verfügen. Die zentrale Rolle der Würde wird dann recht blumig und reichlich redundant, um nicht zu sagen: à la soviétique ausgeführt:

(21") Центральное место среди них занимает идея человеческого достоинства - признание человека высшей общественной ценностью. Реализация этой идеи является подтверждением гуманистических основ и нравственного здоровья общества. Уважать, гарантировать, охранять человеческое достоинство значит уважать и охранять основные жизненные права человека, обеспечить достойные его условия жизни, относиться к нему как к высшей ценности.

Auch das geschäftliche Ansehen erstreckt sich sowohl auf natürliche als auch juristische Personen:

(21"') Под деловой репутацией можно понимать положительную оценку физического или юридического лица, прежде всего как добросовестного предпринимателя, другими участниками имущественного оборота. Применительно к гражданам деловая репутация имеет более широкое содержание, включая соответствующую оценку их профессиональных (не обязательно коммерческих) качеств как специалистов в той или иной области (например, инженеров, адвокатов и т.д.).

Hier zeichnet sich ein weiteres semantisches Problem ab, das uns auf Kap. I zurückwirft: Bei der delovaja reputacija könnte es sich um ein Hyponym von čest' handeln, vgl. die sich wiederholende Formulierung položitel'naja ocenka lica, und beiderorts betrifft dies sowohl natürliche wie juristische Personen (ob der Zusatz social'no značimaja in (20) wirklich distinktiv ist, scheint zweifelhaft). In diesem Fall wäre aber jeder koordinative Konnektor, gleichgültig ob und oder oder, fehl am Platz, da die Koordination kein Hyperonym mit seinem Hyponym verbinden kann, vgl. z.B. *Kinder und kleine Jungs, *Möpse und Hunde, *Donnerstag und Wochentage, etc. ${ }^{31}$

31 Zum Ganzen vgl. E. Lang: Semantik, 106. 
Aufgrund der eben angeführten Begriffsbestimmungen lässt sich rein theoretisch ein Fall voraussagen, wo jemand nur über Würde, aber nicht über Ehre (d.h. den sekundären, komplexeren Begriff) verfügt. Wer dies sein könnte, wird im Lehrbuch nicht ausgeführt. Nach mitteleuropäischem Rechtsempfinden kommen hier zwei Kategorien in Frage, nämlich Tiere und Kinder. Erstere werden durch den russischen Wortlaut in (20) ausgeschlossen, letztere bleiben unerwähnt. Nimmt man nun an, dass čest' $i$ dostoinstvo wirklich im Sinne des logischen und verknüpft sind, so würde Kindern jetzt aufgrund dieser Auslegung von Art. $15^{2}$ des Graždanskij kodeks grundsätzlich kein rechtlicher Schutz zuteil, da die eine Hälfte der Bedingung nie erfüllt ist; wenn jedoch die oder-Verknüpfung zugrunde liegt, wäre dieser Schutz gewährleistet.

Zum Begriffspaar čest' und dostoinstvo liegt eine ausführliche linguistische Begriffsklärung vor, ${ }^{32}$ die unser Interesse schon wegen der Zugehörigkeit ihres Autors zur Moskauer semantischen Schule rund um Ju. Apresjan verdient, die sich u.a. durch ein Maximum an lexikographischer Präzision auszeichnet. Zunächst wird hier von Anfang an der Polysemie beider Begriffe Rechnung getragen: Es geht genauer um dostoinstvo 2 (dostoinstvo 1 hätte demgegenüber die oben erwähnte Bedeutung ,Vorzug') und čest' 1 . Die Unterscheidung zwischen innerer und äußerer Wertschätzung findet sich auch hier, aber sie wird in dem Sinne präzisiert, dass letztere einen bestimmten Verhaltenskodex bzw. ein Regelsystem voraussetzt; dies erklärt z.B., warum man von sud česti oder nevol'nik česti spricht, hingegen nicht von *sud dostoinstva oder *nevol'nik dostoinstva. ${ }^{33}$ Weiter unterliegt dieser Ehrenkodex dem historischen Wandel, der Begriff der Würde dagegen nicht, ja noch mehr: Letzterer tendiert zu universaler Geltung, Ersterer ist auch gruppenspezifisch konzipierbar, vgl. samurajskij kodeks česti, kodeks česti učastnika Associacii rybopromyšlennikov Saxalina (S. 416). ${ }^{34}$ Auch nach Sannikov ist dostoinstvo demzufolge der grundlegendere Begriff, der die Persönlichkeit erst konstituiert; nicht umsonst findet sich auch in der Präambel der Menschenrechtskonvention die Formulierung, dass die Anerkennung der menschlichen Würde zu den Grundlagen von Freiheit, Gerechtigkeit und umfassendem Frieden gehört. ${ }^{35}$ Wichtig erscheint in unserem Zusammenhang auf S. 418 der Hinweis auf Dr. Spock und die Würde des Kindes: ${ }^{36}$

$\begin{array}{ll}32 & \text { V.Z. Sannikov: Ponjatija, 414-425. } \\ 33 & \text { Ebd., 414. } \\ 34 & \text { Ebd., 416. } \\ 35 & \text { Ebd., } 417 . \\ 36 & \text { Ebd., } 418 .\end{array}$


(22) Достоинство, согласно языковой картине мира, в норме присуще всем людям, причем не только взрослым. Ср. „После 6 лет ребенок ... приобретает чувство собственного достоинства и хочет, чтобы его уважали“ (Б. Спок, Ребенок и уход за ним).

Die Tiere finden auch bei Sannikov keine Erwähnung. Der juristisch relevante Begriff reputacija fehlt bei ihm ebenso. Abschließend seien hier seine beiden Definitionen angeführt: 37

(23) $X$-овое достоинство $Y$ - $a$ = нематериальный атрибут человека $\mathrm{Y}$ - сознание собстсвенной высокой ценности как личности или как члена социальной группы X и такое поведение, чтобы эта самооценка не стала ниже.

$X$-овая честь $Y$ - $a$ = нематериальный атрибут человека $Y$ - сознание себя членом социальной группы $\mathrm{X}$ и такое соблюдение моральноэтических правил, принятых для этой социальной группы, чтобы самооценка Y-а или его оценка со стороны других X-ов не стала ниже.

ImVergleich mit derjuristischen Bestimmung fälltdreierlei auf:a)DieDefinition von čest' ist unabhängig von derjenigen von dostoinstvo, b) das Subjekt des Bewusstseins (soznanie) der eigenen Gruppenzugehörigkeit ist hier bei der čest' das Individuum, während oben umgekehrt von seiner Einschätzung (ocenka) durch die Gesellschaft die Rede war; damit spielt das Individuum hier bei dostoinstvo und čest' eine parallele Rolle als Bewussteinsträger. Und schließlich c) enthalten beide Definitionen neben dieser kognitiven Komponente eine Verhaltenskomponente (povedenie bw. sobljudenie), die auf die Erhaltung dieser Selbsteinschätzung gerichtet ist, bei der čest' darüber hinaus auch der Wertschätzung durch die Gruppe. Tatsächlich manifestiert sich z.B. das čuvstvo sobstvennogo dostoinstva durch bestimmte Verhaltensweisen. Schwieriger nachzuvollziehen scheint mir die Perspektivenumkehr bei soznanie sebja členom social'noj gruppy: Intuitiv einleuchtender wirkt hier die juristische Sehweise, die eben dem dt. Ruf entspricht und auch Kollokationen wie poterjat' / sochranit' čest' zugrunde liegt (man verliert bzw. bewahrt ja dabei weder das Bewusstsein seiner Gruppenzugehörigkeit noch die Einhaltung von ethischen Regeln, sondern eben die Wertschätzung der Gruppe). Dass dies das verbreitetste Verständnis der Sprachgemeinschaft widerspiegelt, zeigt auch der Gang ins Internet, das geradezu wimmelt von ähnlichen Umschreibungen, oft

37 Ebd., 419. 
versehen mit didaktisch-moralistischer Ausrichtung. Die folgende Eintragung ist für schulische Zwecke gedacht (Hervorhebung von mir, D.W.):

(24) Что же такое честь? Я ее понимаю как осознанное собственное достоинство (и не только собственное), что вызывает уважение со стороны других, желание подражать твоим поступкам и идти за тобой. Я считаю, что недаром понятие чести человека стоит рядом с его именем, так как собственное имя - это то, что выделяет человека среди других, индивидуализирует его.

(school-essay.ru/chest-dorozhe-vsego-bogatstva.html)

Neu ist hier die Einbeziehung des Eigennamens als ,soziales Gesicht'. In diesem Zusammenhang sei hier auf Art. 23 der Verfassung der Russischen Föderation verwiesen, der statuiert: „každyj graždanin imeet pravo na zaščitu svoej česti $i$ dobrogo imeni“; hier steht der gute Name metaphorisch für Rufbzw. Ansehen.

Andererseits macht sich in (24) auch die russische lexikographische Tradition bemerkbar, vgl. die Eintragung im Tolkovyj slovar' Ušakovs:

(25) чЕсть 1. только ед. Моральное или социальное достоинство, то, что вызывает, поддерживает уважение (к самому себе или со стороны окружающих).

Vergleicht man nun Sannikovs Definitionsvorschlag in (22), so stellt man fest, dass dort die Ušakov'sche alternative Formulierung in der Klammer als „samoocenka Y-a ili ego ocenka so storony drugich X-ov“ wiederkehrt.

Ähnliche Schwierigkeiten bereitet Sannikovs Definition von čest' auch in den strafrechtlichen Definitionen von Ehrverletzungsdelikten. Bei der oskorblenie ist von „umyšlennoe uniženie česti i dostoinstva ličnosti“38 (Art. 130) die Rede; die Substitution ergibt dann uniženie soznanija sebja členom social'noj gruppy, was kaum sehr überzeugend wirkt. Ähnliches gilt für die Verleumdung (kleveta). Letztere wird in Art. 129 definiert als

(26) распространение заведомо ложных сведений, порочащих честь и достоинство другого лица или подрывающих его репутацию.

Auch hier führt die Substitution zu einem unbefriedigenden Resultat, vgl. ... poročaščich soznanija sebja členom social'noj gruppy.

38 Vgl. dazu die Formulierung „verächtlich zu machen oder in der öffentlichen Meinung herabzuwürdigen“ im deutschen StGB, s. Bsp. (20). 
Der angeführte Wortlaut wirft im Übrigen verschiedene inhaltliche Probleme auf. Nicht aus dem Gesetzestext selbst, wohl aber aus dem zugehörigen Kommentar geht hervor, dass hierunter auch die Wiedergabe entsprechender Fremdinformation fällt. ${ }^{39}$ Außerdem aber erweist sich die Forderung der zavedomo ložnych svedenij in der Gerichtspraxis als ausgesprochen selten anwendbar, da der Wahrheitsbeweis der wissentlichen Falschinfomation kaum je erbracht werden kann: Entsprechend scheitern die meisten Verleumdungsklagen vor Gericht. Aus diesem Grunde ist vorgesehen, den Straftatbestand der kleveta bei der nächsten Revision des UK völlig aufzuheben. ${ }^{40}$ Da das russische Strafrecht anders als das deutsche und schweizerische den Tatbestand der üblen Nachrede nicht kennt, bei dem die Komponente der wissentlichen Falschinformation entfällt, bleibt dem Kläger damit in Zukunft nur der zivilrechtliche Weg. Dies illustriert einmal mehr das eingangs in diesem Kapitel Ausgeführte: Die juristische Fachsprache ist auch deswegen historisch variabel, weil das Inventar der Tatbestände einem stetigen Wandel unterliegt. Mehr am Rande sei vermerkt, dass auch die serbische strafrechtliche Bestimmung der Verleumdung unhaltbar ist, allerdings aus dem entgegengesetzten Grund:

(27) BEOGRAD - Uvreda, kleveta, kao i zloupotreba službenog položaja uskoro bi trebalo da budu brisani iz Krivičnog zakonika Srbije (KZS), koji će pak uvesti niz novih krivičnih dela koja srpsko zakonodavstvo treba da usklade sa zakonima Evropske unije.

Kleveta je jedno od retkih krivičnih dela kod kojih je teret dokazivanja na tuženom, koji tokom postupka treba da dokaže da nije oklevetao tužioca.

Sadašnjim rešenjima za klevetu je predviđena novčana kazna koju osuđeni plaća u korist budžeta, pošto je pre par godina ukinuta zatvorska kazna.

(www.kurir-info.rs/crna-hronika/homen-kleveta-se-brise-izkrivicnog-zakonika-)

(Beleidigung, Verleumdung, wie auch der Missbrauch der Dienstposition sollten bald aus dem Strafgesetzbuch Serbiens gestrichen werden, das dafür eine Reihe neuer Straftatbestände einführen wird, die die serbische Gesetzgebung mit den Gesetzen der Europäischen Union abstimmen muss.

39 D. Weiss: Implizitheit, 206.

40 A. Baranov (persönliche Mitteilung, 2011). Unterdessen hat das russische Parlament allerdings im Eilverfahren eine Novellierung des Gesetzes zur Verleumdung verabschiedet, das v.a. eine drakonische Verschärfung des Strafmaßes vorsieht. 
Die Verleumdung ist einer der seltenen Straftatbestände, bei denen die Beweislast dem Angeschuldigten obliegt, der im Lauf des Verfahrens beweisen muss, dass er den Kläger nicht verleumdet hat.

Durch die derzeitigen Bestimmungen über die Verleumdung wird eine Geldstrafe vorgesehen, die die Verurteilten an die Staatskasse entrichten, da die Haftstrafe vor ein paar Jahren abgeschafft wurde.)

Es handelt sich hier möglicherweise um eine europaweit unikale Bestimmung, da die Beweislast nicht bei der Anklage, sondern beim Angeschuldigten liegt. Dies widerspricht u.a. den Rechtsgrundsätzen der Europäischen Union und steht damit dem serbischen Beitrittsantrag im Wege; deswegen soll dieser Artikel gegen Jahresende aufgehoben werden.

Versuchen wir, Bilanz zu ziehen. Bezogen auf den Titel dieser Studie ist zunächst festzuhalten, dass begriffliche Polysemie in der Rechtssprache genauso wenig wünschenswert erscheint wie syntaktische Ambiguität (Kap. I): Das Ideal jeder Fachterminologie bleibt ja eine strikte 1:1-Entsprechung von Ausdruck und Bedeutung. Schwieriger gestaltet sich die Frage nach der Vagheit juristischer Begriffe: Gewiss weisen viele Rechtsbegriffe unscharfe Ränder auf, dies ergibt sich aber als Notwendigkeit aus der Praxis der Rechtssprechung, die ständig mit neuen Sachverhalten konfrontiert wird, welche nie abschließend in irgendeiner Gesetzessammlung aufgelistet werden könnten; entsprechend müssen viele Begriffe möglichst weitgespannt formuliert und flexibel definiert werden. Diese Erkenntnis haben beileibe nicht nur moderne Rechtstheoretiker formuliert: Der polnische Schriftsteller Sebastian Fabian Klonowic, der als Bürgermeister von Lublin selbst Recht sprach, schreibt in seinem „Worek Judaszów“, erschienen 1600 (Hervorhebungen von mir, D.W.):

(28) Choć swięta sprawiedliwość krzywdę cierpi jawną:

Quod iure fit, iuste fit, gdyż insze jest prawo,

A insza sprawiedliwość. O nierządna sprawo!

Możeć być sprawiedliwość bez prawa bo więcej

Przypadków a niżli praw dwakroć sto tysięcy.

Zwłaszcza iż co dzień ludzkich przybywa fortelów.

Nie zstaje paragrafów i prawnych ortylów.

(Obwohl die heilige Gerechtigkeit offenkundiges Unrecht erleidet:

Quod iure fit, iuste fit, da ja Recht das eine ist, Gerechtigkeit etwas anderes. O chaotisches Rechtsverständnis! Es kann sehr wohl eine Gerechtigkeit ohne Recht geben, denn es gibt 200 ooo mal mehr Fälle als rechtliche Bestimmungen. 
Vor allem weil täglich neue menschliche Ränke dazukommen, reichen die Paragraphen und Gerichtsurteile nicht aus.) (S. 209f.)

Entsprechend kommt der laufenden Rechtssprechung auch die Funktion $\mathrm{zu}$, das gesetzte Recht fortzuschreiben. Dieser Grundsatz gilt a fortiori für die grundlegenden Rechtsbegriffe, und hier kommt auch die forensische Linguistik ins Spiel. Der Schreibende hat in zwei Studien die Meinungsfreiheit im Spiegel der russischen Gerichtspraxis beleuchtet; ${ }^{41}$ genauer ging es um die sprachliche Grenzziehung zwischen Tatsachenbehauptungen und Meinungsäußerungen (letztere unter Einschluss der sogen. Vermutungen [predpoloženija]) im Zusammenhang mit Ehrverletzungsdelikten. Die Kritik an der völlig mechanischen Praxis russischer Gerichte führte zur Erkenntnis, dass eine sachgerechte Abgrenzung dieser beiden Kategorien und damit auch eine sprachliche Diagnostik von Meinungsäußerungen den Einsatz von sehr viel linguistischem Sachverstand erfordern würde, da hier zunächst die Rolle der vorkommenden Marker für epistemische Modalität und/oder Evidenzialität wie russ. kažetsja, vrode, kak budto, po-vidimomu, očevidno, navernoe etc. und ihrer kontextuellen Einbettung geklärt werden müsste. Die Diskussion hat auch eine philosophische Seite, da letztlich die Tarski'sche Unterscheidung von Konsens- und Korrespondenzwahrheit ins Spiel gerät. Die durch Verfassung und Menschenrechtskonvention geschützte Meinungsfreiheit erweist sich jedenfalls im Zusammenhang mit Ehrverletzungsdelikten als ausgesprochen schlecht operabel.

Kap. II der vorliegenden Skizze kreiste ebenfalls um Begriffe, die zu den Grundwerten der einzelnen Rechtsordnungen gehören. Dabei erwies sich das russische Paar čest' $i$ dostoinstvo einerseits als phraseologische Einheit, andererseits war das semantische Verhältnis der beiden Konjunkte zueinander kontrovers: Liegt wirklich eine und- oder eher eine oder-Verknüpfung vor? Ist čest' ein semantisches Derivat von dostoinstvo, wie es das juristische Verständnis will, oder sind beide Bedeutungen parallel und voneinander unabhängig, wie Sannikov vorschlägt? Beides Fragen, die ein russisches Gericht wohl als rein akademisch taxieren würde. Die Vermutung liegt nahe, dass das Paar čest' $i$ dostoinstvo in der Praxis als untrennbare Einheit gehandhabt wird, ohne dass die Verletzung beider Komponenten gesondert überprüft würde. Ein neues Problem wirft die häufig in einem Atemzug mit čest' $i$ dostoinstvo genannte delovaja reputacija auf, die eher ein Hyponym der čest' zu sein scheint.

Ein Vergleich mit den deutschsprachigen Entsprechungen hat klar gemacht, dass der Ehre als grundlegendem moralischen Wert bzw. als schützenswertem

41 D. Weiss: Sudebnaja èkspertiza, 265-269 sowie ders.: Implizitheit, 203-213. 
Rechtsgut im deutschsprachigen Raum nicht mehr derselbe Stellenwert zukommt wie in der russischen Sprachgemeinschaft: Aufgrund ihrer historisch bedingten Diskreditierung wird sie heute meist durch unverfänglichere Begriffe wie Ruf, Ansehen oder öffentliche Meinung ersetzt. Allerdings erwies sich an dieser Stelle auch, dass die Jurisprudenz gleichsam mit gespaltener Zunge spricht, da die Ehre in Überschriften, zusammenfassenden Bestimmungen und Kommentaren durchaus noch in Ehren gehalten wird. Mehr der Kuriosität halber sei angemerkt, dass das kroatische Recht das Paar Ehre und Ansehen kennt; ${ }^{42}$ die Definition der Ehre deckt sich dabei weitgehend mit dem russischen Verständnis von dostoinstvo, und überdies gilt: ${ }^{43}$ „Die Begriffe ,Ehre und ,Ansehen“ sind von der Menschenwürde untrennbar [...]“, was zwar an den zentralen Stellenwert der russischen dostoinstvo erinnert, aber die Begriffsverwirrung kaum geringer werden lässt. Noch frappanter im Hinblick auf den deutsch-russischen Kulturvergleich ist aber die Dauerpräsenz der Würde im Verbund mit der Ehre, zumal ja anders als bei der Ehre die Würde der Person zweifellos auch im deutschen rechtsphilosophischen Diskurs positiv besetzt ist. Die Begründung dieser unterschiedlichen Gewichtung überschreitet allerdings den Rahmen einer linguistischen Untersuchung. Jedenfalls zeigen diese Beobachtungen, dass rechtslinguistische Untersuchungen auch für den Vergleich unterschiedlicher Rechtskulturen einen Erkenntnisgewinn abwerfen.

\section{Literatur}

Baranov, Anatolij: Lingvističeskaja èkspertiza teksta. Teoretičeskie osnovanija i praktika

[Linguistische Textexpertise. Theoretische Grundlagen und Praxis]. Moskau 2007

Bojani, Igor: Die Rolle der Ehre im Strafrecht in Kroatien. In: S. Tellenbach (Hrsg.): Die Rolle der Ehre im Strafrecht. Berlin 2007, 408-457

Brinev, Konstantin I.: Teoretičeskaja lingvistika i sudebnaja lingvističeskaja èkspertiza [Theoretische Linguistik und forensische linguistische Expertise]. Barnaul 2009

Fischer, Roswitha (Hrsg.): Sprache und Recht in großen europäischen Sprachen. Juristische Begriffsbildung im Spannungsfeld zwischen Fachsprachlichkeit und allgemeiner Verständlichkeit. Beiträge vom interdisziplinären Symposium am 23./24.4.2009 an der Universität Regensburg 2010

Hoffmann, Ludwig: Wie verständlich können Gesetze sein? In: G. Grewendorf (Hrsg): Rechtskultur als Sprachkultur. Frankfurt 1992, 122-157

42 I. Bojani: Ehre, 408.

43 Ebd., 409. 
Klonowic, Sebastian Fabian: WorekJudaszów [Der Judas-Sack]. Opracowali K. Budzyk, A. Obrębska-Jabłońska. Wrocław 1960

Kuße, Holger: Konjunktionale Koordination in Predigten und politischen Reden. Dargestellt an Belegen aus dem Russischen. München 1998

Lang, Ewald: Semantik der koordinativen Verknüpfung. Berlin 1977

Lerch, Kent D. (Hrsg.): Die Sprache des Rechts. Bd. 1-3. Berlin 2004-5

Levontina, Irina B.: Bukva i zakon: Sudebnaja lingvističeskaja èkspertiza [Buchstabe und Gesetz: Forensische linguistische Expertise]. In: Otečestvennye zapiski [Inländische Notizen]. 2005, Nr. 2. Unter: http://www.strana-oz.ru/2005/2/bukva-izakon-sudebnaya-lingvisticheskaya-ekspertiza (Zugriff: 29.11.2018)

Nussbaumer, Markus: Sprache und Recht. Heidelberg 1997

Osadčij, Michail: Pravovoj samokontrol' oratora [Rechtliche Selbstkontrolle des Redners]. Moskau 2007

Pigolkin, Al'bert S. (Hrsg.):Jazyk zakona [Sprache des Gesetzes]. Moskau 1990

Rathert, Monika: Sprache und Recht. Heidelberg 2006

Sannikov, Vladimir Z.: Kon"junkcija i dis"junkcija v estestvennom jazyke. Na materiale russkich sočinitel'nych konstrukcij [Konjunktion und Disjunktion in der natürlichen Sprache. Am Material russischer koordinativer Konstruktionen]. In: Voprosy jazykoznanija [Fragen der Sprachwissenschaft]. 5 (1990), 50-61

Sannikov, Vladimir Z.: Ponjatija dostoinstva i smirenija [Die Begriffe Würde und Demut]. In: Ju.D. Apresjan (Hrsg.): Jazykovaja kartina mira i sistemnaja leksikografija [Sprachliches Weltbild und systemische Lexikographie]. Moskau 2006, 405-468

Solan, Lawrence M.: The Language of Judges. Chicago 1993

Thieme, Stephanie, Raff, Gudrun, Tacke, Konstatin: Möglichkeiten und Grenzen der sprachlichen Optimierung von Rechtstexten. In: Fischer 2010, 155-168.

Vogel, Carl: Law matters, syntax matters and semantics matters. In: G. Grewendorf, M. Rathert (Hrsg.): Formal Linguistics and Law. Berlin 2009, 25-54

Weiss, Daniel: Umestno li nakazyvat' za publičnoe upotreblenie mata? [Ist es angemessen, den öffentlichen Gebrauch von Mat zu bestrafen?] In: Scando-Slavica. 54 (2008), 198-222

Weiss, Daniel: Sudebnaja èkspertiza i vklad lingvista v interpretaciju zakona [Forensische Expertise und der Beitrag des Linguisten zur Interpretation des Gesetzes]. In: I. Lunde, M. Paulsen (Hrsg.): From Poets to Padonki. Linguistic Authority \& Norm Negotiation in Modern Russian Culture. Bergen 2009 (Slavica Bergensia 9), 252-274

Weiss, Daniel: Implizitheit und Evidenzialität vor Gericht: Zur forensischen Linguistik im heutigen Russland. In: I. Mendoza, T. Reuther (Hrsg.): Slavistische Linguistik 2008/2009. Referate des XXXIV. Konstanzer Slavistischen Arbeitstreffens in Oldenburg, 22.-26. September 2008 und des XXXV. Konstanzer Slavistischen Arbeitstreffens in Salzburg, 21.-25. September 2009. Wiener Slawistischer Almanach 65, 191-215 